\title{
INFLAMMATORY BREAST NEOPLASMS: A SYSTEMATIC REVIEW
}

\author{
Naidhia Alves Soares Ferreira, ${ }^{1,2}$, Sionara Melo Figueiredo de Carvalho', \\ Cintia de Lima Garcia ${ }^{1,2}$, Grayce Alencar Albuquerque ${ }^{1,2}$, Vitor Engrácia Valenti, \\ Thaiany Pedrozo Campos Antunes ${ }^{1}$, Hugo Macedo Jr. ${ }^{1}$, Luiz Carlos de Abreu ${ }^{1,4}$
}

DOI: dx.doi.org/10.7322/jhdg.88974

\begin{abstract}
Overview: Inflammatory Breast Cancer (IBC) is a rare and very aggressive type of cancer that tends to develop at a younger age, compared with other subtypes of breast cancer. Because a distinct lump may not be noticeable, correct diagnosis takes longer and, therefore, successful treatment may hinder a patient's prognostics. This study aims to conduct a systematic review of research articles on IBC. Methods: This is a systematic review of studies in the PubMed database to April 2013, which fit the eligibility criterion - of "Inflammatory Breast Neoplasms" (MeSH Terms), filtered by Languages (English OR Portuguese OR Spanish). Findings: Of the 119studies identified, 25 complied with the eligibility criterion for the disease, diagnostics, treatment and prognostics. Conclusion: Despite methodological differences, findings evidence that although IBC presents particular features (lower survival rate and worse prognostics than most types of breast cancer), very few studies examine its epidemiology and specific risk factors in depth and use any other therapeutic approaches than those commonly used for other breast cancer subtypes. Therefore, further investigation of the disease's aggressiveness is still necessary.
\end{abstract}

Key words: inflammatory breast neoplasms, medical oncology.

\section{INTRODUCTION}

Breast cancer is a public health problem, its incidence increases worldwide. While clinical care focuses on the individual health, the public health policies aimed at breast cancer focus the attention on women from various countries. The goal of these policies is to establish collective guidelines to increase health and quality of life through prevention, treatment of disease and health behavior promotion ${ }^{1}$.

Breast cancer brings number of impacts for women. The challenges and changes resulting from this disease involve many feelings, implying in physical and psychical adaptations ${ }^{2}$.

Inflammatory Breast Cancer (IBC) is a rare, although highly aggressive and lethal ${ }^{3}$ type of cancer. Rapid blood and lymphatic spread and breast tumor emboli are the main features ofIBC ${ }^{4}$. With an average survival rate of three years, IBC accounts for about $2.5 \%$ of all breast cancer types in the US. IBC tends to develop at a younger age than the more common form of breast cancer ${ }^{5}$. Distinct signs and symptoms develop quickly and include redness, thickening (edema/swelling) and ridging or orange-peel like textureof the skin - peaud'orange 4 in French.

African-American women appear to be at higher risk of IBC than white women ${ }^{5,6}$.

The fact that it is a rare form of breast cancer and rarely causes a breast lump, it is harder to diagnose at early stage. Thus, successful prognosis (outlook) and treatment are harder. IBC may be diagnosed by an imaging test and by a breast biopsy of an invasive cancer ${ }^{7}$.

In the past two decades, a multi-therapy approach has increased the rates of clinical response through neoadjuvant chemotherapy, particularly usinganthracyclinesand taxanes-based combination, surgery, radiotherapy and hormonebased therapy ${ }^{5}$.

This study is a systematic review of scientific articles on IBC with reference to the diagnosis, treatment, determinants and prognostics of this type of cancer.

\section{METHODS}

Given that a systematic literature review is directed by a well-formulated question ${ }^{6}$, this study attempts to collate all empirical evidence to answer the following: "What has been researched about inflammatory breast neoplasms?"

A systematic search was conducted on the PubMed MEDLINE database, from its inception to April 2013, originally using the field "MeSH Terms" and Boolean operators (AND; OR) in "PubMed Advanced Search Builder" tool with the following search terms and field: term);

\footnotetext{
1 Laboratório de EscritaCientífica da Faculdade de Medicina do ABC, Santo André -SP, Brazil.

2 Faculdade de Juazeiro do Norte, Juazeiro do Norte - CE, Brazil.

3 Universidade Federal doCariri, Barbalha-CE, Brazil.

4 Universidade de São Paulo, São Paulo - SP, Brazil. Corresponding author:
}

Suggested citation: Ferreira NAS, Carvalho SMF, Garcia CL, et al. Inflammatory breast neoplasms: a systematic review. 24(3): 339-346 Manuscript submitted Sep 10 2014, accepted for publication Nov 212014. 
\# 2 Languages (English OR Portuguese OR Spanish [field]);

The following search was performed: \#1 AND \#2.

Articles were assessed as per their compliance with previously set eligibility criteria, as follows: a) manuscripts written in English, Portuguese or Spanish; b) articles about inflammatory breast neoplasms; c) original articles with online accessible full text; d) prospective or retrospective observational (analytical or descriptive, except case reports), experimental or quasi-experimental studies. Exclusion criteria were: a) other designs, such as case reports, series of cases, review of literature and commentaries; b) non-original studies, including editorials, reviews, prefaces, brief communications and letters to the editor.

Subsequently, every sample was thoroughly examined and data were entered into a matrix for multivariate analysis of author, publication year, description of the study sample and main findings. Studies that dealt with types other than inflammatory breast neoplasms, the focus of this study, were discarded. For each sample, data were extracted independently if co-authored and discrepancies were resolved by consensus. Finally, for heuristic reasons, articles were grouped for discussion in four major themes: profile epidemiology, treatment, factor of prognosis and survival.

\section{RESULTS}

The search strategies initially led to 119 references. After browsing the title and abstract of the retrieved articles for eligibility compliance with inclusion criteria, 94 articles were discarded and 25 articles were further retrieved and included in the final sample (Figure 1).

\section{MEDUNE (via PUBMED) \\ Search term: "inflammatory breast neoplasms" \\ Field: Mesh term, languages \\ Booleand operator. AND, OR \\ Period: from inception of the database to april}

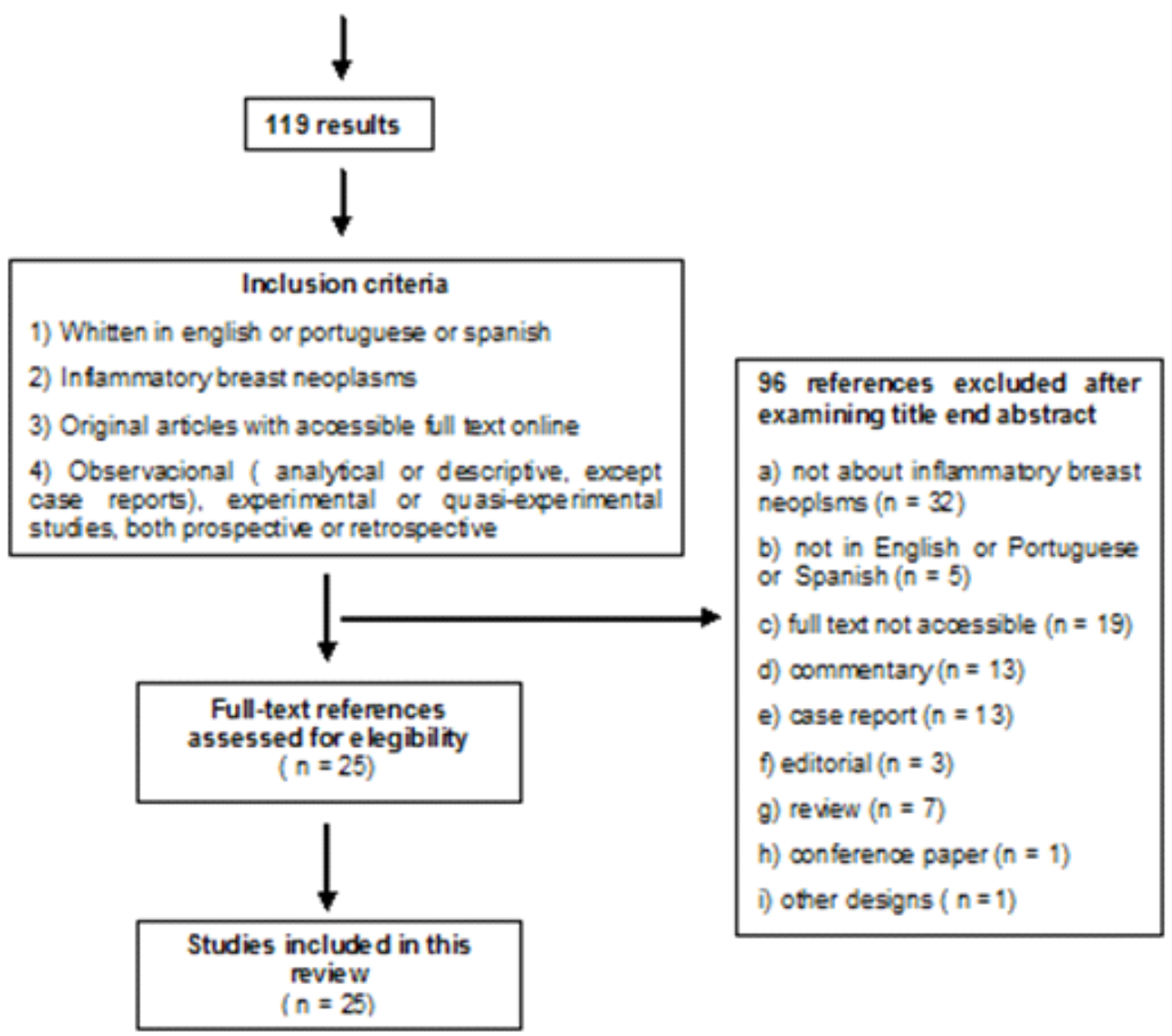

Figure 1. Flow chart showing sample selected for review 
Table 1 provides an overview of the sample selection process which resulted in the 25 studies of the final sample. Such studies were grouped into the three previously set themes: diagnosis and treatment features $^{4,10,12-19,21,23,26,28}$ (14 studies), determinants $5,20,25$ (three studies) and prognostics $^{3,8,9,11,22,24,27,29}$ (eight studies).

Table 1: Inflammatory breast neoplasm: studies and main findings

\section{Author (year)}

Arias-Pulido et al. ${ }^{3}$ (2012)

Nouh et al. ${ }^{4}$

(2011)

Ye et al. 8

(2010)

Gong et al. ${ }^{9}$

(2011)

Andic et al. ${ }^{5}$

(2011)

Le-Petross et al. ${ }^{10}$

(2011)

Dawood et al.11

(2010)

Dawood et al.12 (2012)

Victor et al. ${ }^{13}$

(2011)
Annals of Oncology

\section{Journal}

BMC Cancer

Journal of

ranslational

Medicine

Anticancer

Research

Cancer

Cancer

AJR Women 's Imaging

Annals of Oncology

reast Cancer Research

\section{Sample}

Main findings

117 patients at IIIB VEGF-A in stromal tumor is associated with lower grade

23 IBC and 27 non-IBC

10 primary IBC cases and five non-IBC cases survival rate to breast cancer and recurrence in IBC. When diagnosed at this grade, it might have more effective prognostics leading to customized therapy.

Positive correlation between nodal CTSB and metastatic grade in IBC suggests that thisproteolytic enzyme may lead to nodal metastasis. When Caveolin-1 is found to beoverexpressed in $I B C$, it is likely to activate CTSB at cell surface where IBC spreads into the lymph vessels and develops into metastasis in the lymph nodes.

E-cadherin accumulation and subsequent overexpression is responsible for both MARY-X spheroids as well as the lymph-vascular emboli and fosters. It also fosters resistance to apoptosis and survival advantage. In the setting of the lymph-vascular tumor embolus, E-cadherin does not function as a suppressor gene, but rather as an oncogene.

88 patients who had EZH2 is commonly identified in IBC and is a residual tumor at associated not only with unfavourable prognostics surgery variable, but also with a significant survival rate decline. This might become an innovative IBC treatment option.

55 IBC patients (25 Being Afro American or Caucasian did not appear Caucasian women and 30 Afro-

American women) who underwent

therapy with

curative intention

between 1995 and 2009

to impact adherence to treatment. However, with limited follow-up, there was a trend towards a decreased response to standard multi-therapy treatment and worse outcomes in African American patients than in Caucasian patients. More in-depth follow-up and future studies should be conducted to investigate the impact of race and new-targeted agents in women with IBC.

80 IBC patients who Magnetic Resonance Imaging (MRI) is a major tool took mammogram, ultrasonic and MRI before being submitted to neoadjuvant chemotherapy

203 women with diagnosed II/IV grade IBC, with acknowledged (HER2) and its respective status in IBC diagnosis and staging, since it was successful regarding primary breast disease in nearly $98 \%$ of all patients - unlike mammography today. MR higher and farther-reaching rate of diagnosis makes it a powerful evaluative tool of therapy response.

A highest median survival rate trend was observed in women with Human Epidermal Growth Factor Receptor 2 (HER2)-positive disease. IBC is associated with high grade early brain metastasis, which supports the notion that IBC might become an ideal cohort to assess early detection or preventive intervention aimed at reducing brain metastasis incidence.

women withIII/IV grade IBC, diagnosed between 2004 and 2007

It appears that surgery of the primary IBC tumour at IV grade is associated with improved prognostics, indicating that aggressive treatment both with systemic and local therapy may be advisable for carefully selected groups of women with IV grade IBC.

IBC biopsies conducted for assessing cathepsin $B$ and caveolin-1 expression

In vitro data show that cathepsin B cysteine protease is engaged in type IV collagen degradation and IBC cell invasion, probably by translocating into caveolae so as to regulate cell surface proteolysis. Therefore, clinical approaches aiming to segment active cathepsin $B$ may be effective against IBC. 


\section{Author (year)}

Thomas et al. ${ }^{14}$

(2011)

SHIN, et al. ${ }^{15}$

(2011)

The Brith Jornal

Allensworth et al. ${ }^{16}$

(2012)

Schairer et al. ${ }^{17}$

(2011)

Mandal et al. ${ }^{18}$

(2011)

Martínez

Montemayor

et al. ${ }^{19}$

(2011)

Schlichting

et al. ${ }^{20}$

(2012)

Chaher et $\mathrm{al}^{21}$ (2012)

Sample

Main findings

of Radiology

British

Journal of

Cancer

Reducing GLI1

levels at protein expression, cell proliferation, migration and apoptosis

43 advanced or IBC patients who had undergone neoadjuvant chemotherapy

SUM149 cells generated by

Therapeutics

Breast Cancer

Res Treat

Asterand, Inc with

stable wtXIAP

expression and FG9 vector controls generated by a

lentiviral expression system

274 contralateral invasive breast cancers were identified in IBC cases and 6,019 in non-IBC cases
Apricoxib proved to be an efficient PGE2 inhibitor in twomammalian cell culture lines -

SUM149 and SUM190.27

Nutr Cancer

IBC patient-derived cells

Cancer

Epidemio

Biomarkers Prev

Breast Cancer

Res Treat.

Paraffin blocks of
Non-IBC 5.525 IBC and 337.708 117 primary IBC and 59 non-IBC patients
In the light of observed GLI1 role in proliferation, survival and migration of a subset of IBC cells, direct targeting of GLI1 transcription is suggested as a novel and promising strategy for targeting triple-negative/Basal B IBC modelled by SUM149 cells.

Estimates of residual tumour size based on MRI just before surgery appear to correlate better with pathological results than estimates or predictions based on mammogram, CAT Scans or clinical examination. It may overestimate or underestimate residual disease in some patients. Further studies are needed to assess the value of MRI for evaluating the response and thus the efficacy of chemotherapy earlier in a course of neoadjuvant chemotherapy.

Show that Embelin primes IBC cells for TRAIL (TNFRelated Apoptosis-Inducing Ligand) are mediated by XIAP as a potent inhibitor of caspase activity and unbalanced cell redox state regarding oxidative stress. Therefore, ROS modulators may stand as a promising approach to increase efficacy of TRAIL and IBC based protocols.

Findings highlight importance of vigilant opposite breast screening following IBC diagnosis. MRI proved more accurate to detect breast parenchyma injury. Low IBC survival rates and higher contralateral breast cancer prognosis compared with other types of breast cancer should guide the assessment of risk management strategies for post-IBC contralateral breast cancer.

Shows a highly efficient summary of promising inhibitor of COX-2, apricoxib, a three-step method applied to commercially available samples which improvedã-ketoaldehyde intermediate 7 synthesis. Multigramapricoxib quantities prepared for preclinical trials proved to be inhibitors of COX-2 in IBC cells.

Reishi is a potent anti-invasion agent to prevent tumour spheroid formation and potential inhibitor of IBC spread, whose action can be correlated with reduced viability and inhibition of eIF4G, Ecadherin, MMP-9 and p120-catenin, key proteins responsible for tumour growth and IBC invasion. Findings suggest that Reishi extract could be used as a novel anticancer therapy for IBC patients.

Low socio-economic status women have less access to health services and, therefore, to earlier breast cancer detection.

Findings show lower survival rate in IBC patients irrespective of hormone, chemo and radio therapy. Antracycline-based chemo with or without one-year administration of trastuzumab (pre-surgery followed by adjuvant) showed that trastuzumab resulted in significantly higher pathological response and free-of-event survival rate in HER2positive patients. 


\begin{tabular}{|c|c|c|c|}
\hline Author (year) & Journal & Sample & Main findings \\
\hline $\begin{array}{l}\text { LI et al. }{ }^{22} \\
(2011)\end{array}$ & The Oncologist & $\begin{array}{l}316 \text { IBC patients, } \\
\text { without distant } \\
\text { metastasis }\end{array}$ & $\begin{array}{l}\text { A subtype of breast cancer, as established by ER, PR } \\
\text { and HER-2 substitute markers, is closely associated } \\
\text { with OS and LRR findings in IBC patients. TN subtype } \\
\text { consistently anticipated worst findings. Results can be } \\
\text { useful in establishing therapies for distant and } \\
\text { locoregional disease. }\end{array}$ \\
\hline $\begin{array}{l}\text { Ohshiro et al. }{ }^{23} \\
(2012)\end{array}$ & PLOS ONE & $\begin{array}{l}\text { SUM149A cell lines } \\
\text { from primary duct } \\
\text { carcinoma; } \\
\text { SUM190 from IBC } \\
\text { cells. MDA-MB-231 } \\
\text { breast cancer cell } \\
\text { lines, MDAMB-468 } \\
\text { and MCF-7 from } \\
\text { American } \\
\text { TypeCulture } \\
\text { Collection }\end{array}$ & $\begin{array}{l}\text { Provides evidence for } \mathrm{p}-\mathrm{RK} 1 \text { / } 2 \text { supra-regulation } \\
\text { through immunocoloration of IBC samples and } \\
\text { suggests a non-genomic signaling role through } \\
\text { p-ERK } 1 / 2 \text { activation related to IBC hormone } \\
\text { dependence through a combination of estrogen } \\
\text { receptors. }\end{array}$ \\
\hline $\begin{array}{c}\text { Bertucci et al. }{ }^{24} \\
(2012)\end{array}$ & PLOS ONE & $\begin{array}{c}\text { Invasive } \\
\text { adenocarcinoma } \\
\text { tissue samples } \\
\text { were collected from } \\
359 \text { patients who } \\
\text { had been } \\
\text { submitted to } \\
\text { surgery biopsy or } \\
\text { initial surgery at } \\
\text { Institut Paoli- } \\
\text { Calmettes }\end{array}$ & $\begin{array}{l}\text { These findings explain the failure of anti-estrogen } \\
\text { traditional therapies for ER-positive IBC that induce } \\
\text { non-genomic signalling. It also makes the case for } \\
\text { modified therapies using these estrogen receptors. } \\
\text { Monitoring this specific germinal variationcan become } \\
\text { a critical tool in IBC prognostics. Additionally, it is } \\
\text { suggested that allelic risk, when associated with low } \\
\text { sensitivity, can be correlated with high metastasis risk. }\end{array}$ \\
\hline $\begin{array}{l}\text { Duke et al. }{ }^{25} \\
(2010)\end{array}$ & $\begin{array}{l}\text { Oncology } \\
\text { reports }\end{array}$ & $\begin{array}{c}18 \text { people from the } \\
\text { same workplace - } \\
\text { three IBC and } 15 \\
\text { non-IBC cases }\end{array}$ & $\begin{array}{l}\text { Combined workplace factors cannot account for the } \\
\text { three IBC cases. However, every woman was directly } \\
\text { exposed to tumour-associated agents and/or factors. } \\
\text { Long-lasting workplace conditions may have led to the } \\
\text { development of aggressive breast cancer. }\end{array}$ \\
\hline $\begin{array}{l}\text { BOURGIER et } \\
\text { al. }{ }^{26}(2010)\end{array}$ & $\begin{array}{c}\text { Int. J. Radiation } \\
\text { Oncology Biol. } \\
\text { Phys }\end{array}$ & $\begin{array}{l}124 \text { patients with } \\
\text { non-metastatic IBC }\end{array}$ & $\begin{array}{l}\text { Alternating chemo and radiotherapy yielded efficient } \\
\text { long-term local control without surgery. Long-term MFS } \\
\text { and OS rates were similar to those that resulted from } \\
\text { primary chemotherapy, total mastectomy and adjuvant } \\
\text { radiotherapy. IBC continues to have a dismal prognosis } \\
\text { and the current approach, safely combining radiation } \\
\text { therapy and systemic treatments, should be } \\
\text { reassessed when suitable targeted agents become } \\
\text { available. }\end{array}$ \\
\hline $\begin{array}{l}\text { Sesgin et al. }{ }^{27} \\
\text { (2011) }\end{array}$ & Med PrincPract & $\begin{array}{l}45 \text { patients withIBC } \\
\text { who had developed } \\
\text { distant metastasis }\end{array}$ & $\begin{array}{l}\text { Patients with p53 protein accumulation and visceral } \\
\text { organ involvement appear to have a significantly } \\
\text { shorter survival rate than those without such poor } \\
\text { prognosis. p53 status and presence or absence of } \\
\text { visceral metastasis are clinically useful tools for } \\
\text { prognosis and risk stratification in metastatic IBC. } \\
\text { However, larger prospective studies will be needed to } \\
\text { confirm these findings. }\end{array}$ \\
\hline $\begin{array}{l}\text { Mailliez et al. }{ }^{28} \\
\quad(2010)\end{array}$ & $\begin{array}{c}\text { The Breast } \\
\text { journal }\end{array}$ & $\begin{array}{l}56 \text { had a local- } \\
\text { regional IBC with } \\
\text { available } \\
\text { histopathologic } \\
\text { material }\end{array}$ & $\begin{array}{l}\text { Study proposes a standardised sampling process with } \\
\text { a mastectomy at scale scheme with samplings of } \\
\text { residual tumour or cicatricial area collected every } \\
\text { centimetre and noted down on the scheme. } \\
\text { Additionally, another sampling to be systematically } \\
\text { collected in each quadrant, two samplings on the nipple } \\
\text { and one behind the nipple to evaluate tumour size. }\end{array}$ \\
\hline $\begin{array}{c}\text { Schlichting et } \\
\text { al.29 } \\
(2012)\end{array}$ & $\begin{array}{l}\text { Breast Cancer } \\
\text { Res Treat }\end{array}$ & & $\begin{array}{l}\text { Findings indicate IBC patients have lower survival rate } \\
\text { than non-IBC patients, most specifically for stage III } \\
\text { cancers. Residing in a lower SEP, non-metro county } \\
\text { may worsen BCS survival, though this was only } \\
\text { significant for non-IBC in multivariate proportional } \\
\text { hazards models. Afro-Americans appear to have lower } \\
\text { BCS survival regardless of inflammatory status, stage, } \\
\text { county level SEP, tumour, or treatment features. }\end{array}$ \\
\hline
\end{tabular}




\section{Determining features}

Only three of the study samples $5,20,25$ investigated determining features of the disease. For Andicet al. ${ }^{5}$, no difference was assessed between races at middle age, tumour size and receptor grade and status. However, a trend emerged for pathologic response, which was slightly higher in Caucasian than in Afro-American women $(P=0,23)-a$ generally higher survival rate (three years) in Caucasian than in Afro-American women $(P=0,09)$ and higher survival rate of distant metastasis $(P=0,19)$. Racial features did not seem to affect adherence to treatment.

Two studies ${ }^{5,}{ }^{20}$ suggest that low socioeconomic status is associated with higherIBC incidence, irrespective of a patient's age/race/ethnic group at diagnosis, and possibly associated with lower educational level and poor access to health services.

Duke et al. ${ }^{25}$ investigated three specific cases of IBC in the workplace within a time-span of 10 months, suggesting that oral contraceptives, hormone replacement therapy, overweight and exposure topesticides and herbicides might have combined to result in such an unordinary number ofIBC cases in the workplace. However, they did not explain how combined workplace factors affected the three people.

\section{Diagnostics and treatment}

Several studies investigated diagnosis and treatment ${ }^{4,10,12-19,21,23,26,28}$, two of which ${ }^{10,15}$ show that MRI (Magnetic Resonance Imaging) is significantly more accuracy for diagnosing IBC. LePetross ${ }^{9}$ argues that MRI has a $98 \%$ accuracy rate in targeting IBC when compared with ultrasonic imaging (94\%) and a mammogram (65\%). MRI may also aid in assessing response to therapy. The samples contradict current practices to track breast cancer, of which the mammogram is the most commonly used. Vigilant opposite breast screening using MRI should be considered given the Iow IBC survival rates and higher contralateral breast cancer prognosis compared with other types of breast cancer ${ }^{17}$.

With reference to treatment options, primary grade IV IBC surgery is associated with better prognostics, suggesting that systemic or local therapy may be advisable for carefully selected objects $^{13}$. Nevertheless, Bourgieret al. ${ }^{26}$ monitored 124 women from the time their non-metastasis IBS was diagnosed and suggest alternating chemo and radiotherapy as an effective method for long-term control without surgery. Chaher et al. ${ }^{21}$, however, observed worse survival conditions in IBC patients, irrespective of their being submitted to chemo, radio or hormone therapy.

Some studies suggest novel treatments using biological markers ${ }^{4,13}$. Victor et al. ${ }^{13}$ contend that cathepsin B cysteine protease is engaged in type IV collagen degradationand IBC cell invasion, probably by translocating into caveolae so as to regulate cell surface proteolysis. These in vitro findings are supported by significant cathepsin B and caveolin-1 co-expression in IBC cell samples. Theirs is one of the few studies which show that cathepsin $B$, associated with caveolin-1, plays a role in aggressive phenotype of IBC.

Two studies investigated plant active principles. Martínez-Montemayor et al $^{19}$ examined the use of Reishi extract, a potent anti-invasion agent to prevent tumour spheroid formation and potential inhibitor of IBC spread and action can be correlated with reduced viability and inhibition of eIF4G, E-cadherin, MMP-9 and p120-catenin - key proteins responsible for tumour growth and IBC invasion. It is suggested that Reishi extract could be used as a novel anticancer therapy for IBC patients. Allensworth et al. ${ }^{16}$ described the role played by apoptosis inhibitor related to $\mathrm{X}$ when embelin, derived from a plant, is used in combination withTRAIL - a proapoptotic receptor agonist - to catalyse the death of this receptor. Cell viability was lowered and TRAIL proved to be a novice approach to higher IBC protocol.

GLI1 is a protein-coding gene that is able to regulate cell proliferation, survival and differentiation. Thus, Thomas et al. ${ }^{14}$ suggested direct targeting of GLI1 transcription as a promising strategic therapy for IBC patients.

Ohshiro et al. ${ }^{23}$ explored non-genomic signalling of several estrogen and anti-estrogen agents in IBC SUM149 and SUM190 cell lines and identified a variant estrogen receptor (EEI), ERa36, in SUM149 and SUM190 cells and a substantial increase in cell migration and invasion of SUM149 cells when these ligands were used. Such findings suggest a non-genomic signalling role through $\mathrm{p}$ ERK1/2 activation related to IBC hormone dependence through a combination of estrogen receptors, and explain the failure of anti-estrogen traditional therapies for ER-positive IBC.

Mailliezet al. ${ }^{28}$ compared the Complete Pathologic Response(CPR) in 56 non-metastasis IBC patients and assessed a possible correlation betweenCPR and global survival. Initial biopsies and mastectomy at scale scheme with samplings of residual tumour or cicatricial area were revised by the same pathologist. A $75 \%$ clinical response was found, but no correlation between clinical and pathological response. Neither response was predictive of global relapse-free survival.

\section{Prognostics}

Prognostics-oriented studies explore mainly biological factors that are good prognostics markers $3,8,9,11,22,24,27,29$.

Seszinet al. ${ }^{27}$ assessed prognostics markers of IBC by examining resection samples of 45 IBC patients who had developed distant metastasis. Patients with p53 protein accumulation and visceral organ involvement appear to have a significantly shorter survival rate than those without such poor prognosis.

EZH2, Enhancer of homolog zester2, is a Polycomb protein that regulates cell cycle progression and which is associated with many malign tumours, including breast cancer. It is associated not only with unfavourable prognostics variable but also with a significant survival rate decline $^{9}$. Therefore, it might become an innovative IBC treatment option. 
Expression of VEGF-A, Vascular endothelial growth factor $A$, in stromal tumour, is associated with lower survival rate to breast cancer and recurrence in IBC. When diagnosed at this grade, it might have more effective prognostics leading to customised therapy.

In the research of Para Ye et al. ${ }^{8}$, E-cadherin accumulation and subsequent over-expression is responsible for both MARY-X spheroids and the lymph-vascular emboli and fosters. It also fosters resistance to apoptosis and survival advantage. In the setting of the lymph-vascular tumor embolus, E-cadherin does not function as a suppressor gene, but rather as an oncogene.

Two studies assessed hormone receptors ${ }^{11,24}$. Dawoodet al. ${ }^{11}$ studied 203 women with diagnosed II/IV grade IBC, with acknowledged (HER2) and its respective status and cumulative incidence or brain metastases. A highest median survival rate trend was observed in women with Human Epidermal Growth Factor Receptor 2 (HER2)-positive disease. IBC is associated with high grade early brain metastasis, which supports the notion that IBC might become an ideal cohort to assess early detection or preventive intervention aimed at reducing brain metastasis incidence.

Between 1989 and 2008, Li et al. ${ }^{22}$ analysed the records of 316 patients without distant metastasis, most of whom were submitted to neoadjuvant chemotherapy, mastectomy and post-mastectomy radiotherapy. These objects were grouped according to the status of the estrogen receptor, progesterone and human epidermal growth factor receptor -2 . They found that the disease triple-negative is associated with lower global and locoregional relapse survival, thus showing the need to develop therapies for distant and locoregional disease.

\section{REFERENCES}

1. Hani K. Atrash 1, Richard Carpentier The evolving role of public health in the delivery of health care. Journal of Human Growth and Development, 2012; 22 (3): 396-99.

2. Ariana Machado Toriy, EditKrawulski, Jaqueline de Souza Viera Brasiliense, Clarissa Medeiros da Luz, Fabiana FlowersSperandio. Perceptions, feelings and physical and emotional experiences of woman after breast cancer. Journal of Human Growth and Development, 2013; 23 (3): 303-08.

3. Arias-Pulidoet al. Tumor stromal vascular endothelial growth factorA is predictive of poor outcome in inflammatory breast cancer BMC Cancer 2012, 12:298.

4. Nouh, M. A. et al. Cathepsin B: a potential prognostic marker for inflammatory breast cancer. Journal of translational medicine9, 1, doi:10.1186/1479-5876-9-1 (2011).

5. Andic, F. et al. Treatment adherence and outcome in women with inflammatory breast cancer: does race matter? Cancer117, 54855492, doi:10.1002/cncr.26187 (2011).
Bertucciet al. ${ }^{24}$ suggested, initially described as a low susceptibility locus and penetrance forcolorectal and prostate cancer, seems to be associated with high IBC metastasis risk. New prognostic tools, currently based on histoclinic and somatic mutation factors, may benefit from monitoring the specific IBC patient germinative variations. As this was the first study to present such findings, the authors suggested further investigation to verify this association.

Although IBC risk factors remain unknown, some studies have shown diverse features for IBC and non-IBC patients. Few studies have examined the rarest pathologies of this type of cancer and are thus inaccurate in assessing consistently inherent risk factors.

Therefore, it is paramount that early IBC diagnosis is implemented, especially for low socioeconomic groups, who are likely to have less access to healthcare and early detection programmes, as early diagnosis is viewed as possibly having a direct positive effect on prognostics.

It should be noted that the mammogram remains the most commonly used method to detect breast cancer. However, evidence shows that MRI is a more accurate diagnostic tool as IBC clinical features are taken into account.

Few studies have examined IBC molecular biology as it is rare. Nevertheless, as we consider this disease's high aggressiveness, low survival rate and resistance to treatment, further investigation must be pursued. The sample of this study has not identified different and effective types of treatment, but found new proposed ways to enhance IBC treatment using novice biological markers, as discussed above.

6. Hance KW, A. W., Devesa SS, et al. Trends in, the, i. b. c. i. a. s., surveillance, e., and end results program at the, 2005;97:966-, N. C. I. J. N. C. I. \& 975.

7. Moher D, L. A., Tetzlaff J, Altman DG. Preferred reporting items for systematic reviews and meta-analyses: the PRISMA statement. PLoS Med. 2009;6(7):e1000097.

8. Ye, Y., et al. (2010). E-cadherin accumulation within the lymphovascular embolus of inflammatory breast cancer is due to altered trafficking.Anticancer Research, 30(10), 390310.

9. Gong, Y. et al. Polycomb group protein $\mathrm{EZH} 2$ is frequently expressed in inflammatory breast cancer and is predictive of worse clinical outcome. Cancer117, 5476-5484, doi:10.1002/ cncr.26179 (2011).

10. Le-Petross, H. T. et al. MRI features of inflammatory breast cancer. AJR. American journal of roentgenology197, W769-776, doi:10.2214/AJR.10.6157 (2011).

11. Dawood, S. et al. Incidence of and survival following brain metastases among women with inflammatory breast cancer. Annals of oncology: 
official journal of the European Society for Medical Oncology / ESMO21, 2348-2355, doi:10.1093/annonc/mdq239 (2010).

12. Dawood, S. et al. Identifying factors that impact survival among women with inflammatory breast cancer. Annals of oncology: official journal of the European Society for Medical Oncology / ESMO23, 870-875, doi:10.1093/ annonc/mdr319 (2012).

13. Victor, B. C., Anbalagan, A., Mohamed, M. M., Sloane, B. F. \& Cavallo-Medved, D. Inhibition of cathepsin B activity attenuates extracellular matrix degradation and inflammatory breast cancer invasion. Breast cancer research : BCR13, R115, doi:10.1186/bcr3058 (2011).

14. Thomas, Z. I. et al. Targeting GLI1 expression in human inflammatory breast cancer cells enhances apoptosis and attenuates migration. British journal of cancer104, 1575-1586, doi:10.1038/bjc.2011.133 (2011).

15. Shin, H. J. et al. Comparison of mammography, sonography, MRI and clinical examination in patients with locally advanced or inflammatory breast cancer who underwent neoadjuvant chemotherapy. The British journal of radiology $84,612-620$, doi: $10.1259 / \mathrm{bjr} /$ 74430952 (2011)

16. Allensworth, J. L., Aird, K. M., Aldrich, A. J., Batinic-Haberle, I. \& Devi, G. R. XIAP inhibition and generation of reactive oxygen species enhances TRAIL sensitivity in inflammatory breast cancer cells. Molecular cancer therapeutics11, 1518-1527, doi:10.1158/ 1535-7163. MCT-11-0787 (2012).

17. Schairer, C., Brown, L. M. \& Mai, P. L. Inflammatory breast cancer: high risk of contralateral breast cancer compared to comparably staged non-inflammatory breast cancer. Breast cancer research and treatment129, 117-124, doi:10.1007/s10549010-1324-y (2011).

18. Mandal, P. K., Freiter, E. M., Bagsby, A. L., Robertson, F. M. \& McMurray, J. S. Efficient synthesis of apricoxib, CS-706, a selective cyclooxygenase-2 inhibitor, and evaluation of inhibition of prostaglandin E2 production in inflammatory breast cancer cells. Bioorganic \& medicinal chemistry letters21, 6071-6073, doi:10.1016/j.bmcl.2011.08.050 (2011).

19. Martinez-Montemayor, M. M., Acevedo, R. R., Otero-Franqui, E., Cubano, L. A. \& Dharmawardhane, S. F. Ganoderma lucidum (Reishi) inhibits cancer cell growth and expression of key molecules in inflammatory breast cancer. Nutrition and cancer63, 10851094, doi: 10.1080/01635581.2011.601845 (2011).
20. Schlichting JA, et al. Association of inflammatory and noninflammatory breast cancer with socioeconomic characteristics in the Surveillance, Epidemiology, and End Results database, 2000-2007.Cancer Epidemiol Biomarkers Prev 21, 155.doi: 10.1158/105599652012

21. Chaher, N. et al. Molecular and epidemiological characteristics of inflammatory breast cancer in Algerian patients. Breast cancer research and treatment131, 437-444, doi:10.1007/s10549011-1422-5 (2012).

22. Li, J. et al. Triple-negative subtype predicts poor overall survival and high locoregional relapse in inflammatory breast cancer. The oncologist 16, 1675-1683, doi:10.1634/ theoncologist.2011-0196 (2011).

23. Ohshiro K, Schwartz AM, Levine PH, Kumar R .Alternate Estrogen Receptors Promote Invasion of Inflammatory Breast Cancer Cells via NonGenomic Signaling. PLoS ONE 7(1): e30725. doi:10.1371/journal.pone.0030725 (2012).

24. Bertucci, F. 8q24 cancer risk allele associated with major metastatic risk in inflammatory breast cancer. PLoS One 7(5),doi:10.1371/ journal.pone.0037943.t001 (2012)

25. Duke T J, Nasreen C. Jahed, C C. Veneroso, R $R$, Owen J, Daniel $H$. et al. A cluster of inflammatory breast cancer (IBC) in an office setting: Additional evidence of the importance of environmental factors in IBC etiology. Oncology reports24, doi:10.3892/or_00000983 (2010).

26. Bourgier $\mathrm{C}$ et al. Exclusive Alternating Chemotherapy and Radiotherapy in Nonmetastatic Inflammatory Breast Cancer: 20 Years of Follow-Up. International Journal of Radiation Oncology, Biology, Physics 82(2) 690695, (2012).

27. Sezgin C et al. p53 protein accumulation and presence of visceral metastasis are independent prognostic factors for survival in patients with metastatic inflammatory breast carcinoma. Med PrincPract 20(2):159-64. doi: 10.1159/ 000319916. (2011).

28. Mailliez et al. Is there a reliable method to assess the complete pathologic response on the tumor after eo-adjuvant chemotherapy in inflammatory breast cancer toward recommendations for the pathologic process? Experience in 56 patients treated in a single institution. Breast J 16(5):464-71. doi: 10.1111/j.1524-4741.2010.00957 (2010).

29. Schlichting $J A$, et al. Inflammatory and noninflammatory breast cancer survival by socioeconomic position in the Surveillance, Epidemiology, and End Results database, 19902008. BreastCancer Res Treat 134(3), 125768(2012). 29 